\title{
Diagnosis of Acute Appendicitis- A Never-ending Story
}

\author{
Mohammad Vaziri* \\ Minimally Invasive Surgery Research center, Iran University of Medical Sciences, Iran \\ *Corresponding author: Mohammad Vaziri, Thoracic Surgeon, Minimally Invasive Surgery Research center, Iran University of \\ Medical Sciences, Tehran, Iran
}

\begin{tabular}{ll} 
ARTICLE INFO & ABSTRACT \\
\hline
\end{tabular}

Received: 幽 May 01, 2019

Published: 蔧 May 07, 2019

Citation: Mohammad Vaziri. Diagnosis of Acute Appendicitis- A Never-ending Story. Biomed J Sci \& Tech Res 17(5)2019. BJSTR. MS.ID.003055.
Abbreviations: AA: Acute Appendicitis; WBC: White Blood Cell; CRP: C-Reactive Protein; IL6: Inter Leukin-6; MPV: Mean platelet volume; PDW: Platelet Distribution Width; G-CSF: Granulocyte Colony-Stimulating Factor; LRG: Leucine-Rich a-2-Glycoprotein; PCT: Procalcitonin; SAA: Serum Amyloid A

\section{Introduction}

The purpose of this article is to present a concise summary of the latest findings in the diagnostic workup of appendicitis. The reader is recommended to make decisions in a clinical setting by using his or her clinical expertise in the context of patient's characteristics and best available evidence. Acute Appendicitis (AA) remains one of the most common diseases faced by the surgeon in practice. It is estimated that as much as $6 \%$ to $7 \%$ of the general population will develop appendicitis during their lifetime, and despite its high prevalence, the diagnosis of acute appendicitis can be challenging [1]. Acute appendicitis is the second most common diagnosis leading to malpractice claims against emergency physicians after acute myocardial infarction. No clinical presentation has been demonstrated to be predictive of appendicitis. The same may be said of laboratory evaluations, which are also weakly predictive when considered in isolation. Rather, it is the assessment of the collective body of information that allows more precise diagnosis [2]. Numerous biochemical parameters have been used to enhance and refine the clinical diagnosis of AA including [3] white blood cell (WBC) count, C-reactive protein (CRP), interleukin-6 (IL6), Procalcitonin, hyperbilirubinaemia, neutrophil-to-lymphocyte ratio, Mean platelet volume (MPV) and platelet distribution width (PDW) , Serum Amyloid A ,Granulocyte colony-stimulating factor (G-CSF), Urine Leucine-rich a-2-glycoprotein (LRG) and S100A8/ A9 (Cal-protectin).

CRP can be regarded as a predictor for complicated or late-stage appendicitis but it is not useful for early diagnosis. The evidence suggests acute appendicitis can be excluded when WBC, CRP and PMN ratio are all within normal limits. No diagnosis of appendicitis should be made based on increase of a single blood marker [4]. Studies confirm a relationship between IL-6 levels and the early phase of appendicitis, but it has not been demonstrated firmly to be better than other blood markers in the diagnosis of appendicitis [5]. Serum total/direct bilirubin estimation, which is a simple, cheap, and easily available test in every laboratory can be added to the routine evaluation list of suspected cases of acute appendicitis. Hyperbilirubinemia, especially with elevated direct bilirubin levels, may be viewed as an important marker for the prediction of appendiceal gangrene/perforation [6-8]. Procalcitonin (PCT) measurement cannot be recommended as a diagnostic test for patients with acute appendicitis and its routine use in such patients is not conclusive. The PCT values can be used as a prognostic marker and predictor of infectious complications following surgery for acute appendicitis and it can help to carry out timely surgical intervention, which is highly recommended in patients with values more than $0.5 \mathrm{ng} / \mathrm{ml}[9]$.

Mean platelet volume (MPV) can change according to the stage of inflammation-associated diseases, such as ulcerative colitis, familial Mediterranean fever, and sepsis. MPV values in cases of appendicitis without perforation were lower than in cases of appendicitis with perforation. It is not considered a diagnostic test [10]. Serum Amyloid A (SAA) is a non-specific marker of inflammation which can be useful in the early diagnosis of 
appendicitis, but further studies are needed to prove this argument [11]. Granulocyte colony-stimulating factor (G-CSF) acts on the bone marrow to stimulate production and release of granulocytes into the peripheral blood. It is associated with the severity of inflammation. It has the potential to aid other diagnostic measures while also signifying the severity of acute appendicitis [3]. Urine Leucine-rich a-2-glycoprotein (LRG) has been demonstrated to be helpful as a diagnostic marker for acute appendicitis in children. LRG has been found to be elevated in patients with acute appendicitis in the absence of macroscopic changes [12]. S100A8/ A9 (Cal-protectin), a calcium-binding protein, is correlated with acute inflammation specific of the gastrointestinal tract.

Calprotectin (Cal) is an antimicrobial protein and constitutes about $60 \%$ of cytosolic proteins in neutrophil granulocytes. It is secreted into the intestinal lumen during the early phases of intestinal mucosal damage. The transfer of inflammatory cells via the lumen of the vermiform appendix into the colonic lumen makes it possible to measure Cal in stool of patients with suspected appendicitis [13] Fecal calprotectin could be helpful in screening patients with right lower quadrant pain suspected of acute appendicitis or infectious enteritis. Currently, fecal calprotectin has been identified as a valuable diagnostic marker for a series of bowel pathologies, e.g. chronic inflammatory bowel diseases [14]. An intuitive approach to diagnosis of appendicitis is to recruit a biomarker panel, the APPY $1^{\text {TM }}$ test, which consist of the combined values of total white blood cell count (WBC), plasma C-reactive protein (CRP) level and plasma myeloid related protein 8/14 (MRP 8/14 or calprotectin) level in a proprietary mathematical algorithm expressed as 0.1177 (WBC k/ $\mu \mathrm{l})+0.0202(\mathrm{CRP} \mu \mathrm{g} / \mathrm{ml})+1.6(\mathrm{MRP} 8 / 14 \mu \mathrm{g} / \mathrm{ml})+2.4372=\mathrm{A}$, with A being a single numerical value [15]

The results suggest that adult patients with abdominal pain for whom acute appendicitis is the primary diagnosis might have imaging postponed in favor of clinical observation in the setting of low risk results on the APPY1 test or with negative results for both WBC and CRP. A variety of radiographic studies may be used to diagnose appendicitis. These consist of plain radiographs, computed tomography (CT) scanning, ultrasound (US), and magnetic resonance imaging (MRI). CT scanning is the most common imaging study to diagnose appendicitis and is highly effective and accurate. The recommended imaging protocol from the Infectious Diseases Society of America (IDSA) and the Surgical Infection Society includes the intravenous administration of contrast material only. Oral and rectal administration of contrast material is not recommended [16,17].

CT is not recommend in cases in which appendicitis is strongly suspected on clinical grounds due to disadvantages including radiation exposure, risk of contrast induced nephropathy, and cost. Additionally, the time required for performance of CT, particularly when oral contrast is needed, may add substantially to ED length of stay, a contributing factor to ED crowding. Abdominal US is the preferred imaging modality to evaluate children with suspected appendicitis because it has good diagnostic performance, lacks ionizing radiation and does not require intravenous contrast agents [18]. Various scoring systems including the Alvarado, Samuel, Tzanakis, Ohmann, Eskelinen, Fanyo, Lindberg and Logistic score of Kharbanda have been developed to aid in the diagnosis of AA in order to decrease negative appendectomy rates. The Alvarado score, derived from retrospectively collected data from 305 adult patients in the mid-1980s, is the best-known clinical prediction rule for estimating the risk of appendicitis. The Alvarado scoring system most accurately predicts appendicitis in men and can be used as a reasonable starting point in the assessment of suspected appendicitis cases [19].

A new score, namely MESH (Migration, Elevated WBC, shift to left, and Heel drop test) score has been introduced recently to further facilitate the diagnosis of appendicitis. Heel drop test is conducted as follows: patients are asked to look at the face of the physician running the test and come down with all his/her weight on his/her heels after standing on his/her toes on a smooth surface. During this exercise, findings indicative of perceived pain is evaluated as a positive result in the heel drop test [20]. While the heel drop test was originally introduced to evoke peritoneal irritation by moving intraperitoneal contents up and down and to detect the presence or absence of peritonitis, especially in acute appendicitis, it is also considered the most sensitive test for meningitis [21]. Another score, The Raja Isteri Pengiran Anak Saleha appendicitis (RIPASA) score was developed in 2010 in Brunei (Table 1) and tested and replicated in Asian and Middle Eastern populations in Pakistan, China, India, Egypt and Saudi Arabia. It is comprised of 15 demographics, clinical and laboratorybased parameters and has a sensitivity of $97 \%$ and specificity of $81 \%$ for AA in Eastern populations at a cut-off score of 7.5. The RIPASA score is a simple, non-invasive and rapid scoring system [22]. Diagnosis of appendicitis remains a never-ending story and a valid, reliable, sensitive, specific, minimally invasive, and low-cost test is eagerly awaited.

Table 1: RIPASA Scoring System.

\begin{tabular}{|c|c|}
\hline Diagnostic Criteria & Value \\
\hline Sex & 1.0 \\
\hline Male & 0.5 \\
\hline Female & \\
\hline Age & 1.0 \\
\hline$\leq 39.9$ years & 0.5 \\
\hline$\geq 40$ years & 0.5 \\
\hline RLQ pain & 0.5 \\
\hline Migration of RLQ pain & 1.0 \\
\hline Anorexia & 1.0 \\
\hline Nausea and/or vomiting & \\
\hline Duration of symptoms & \\
\hline
\end{tabular}




\begin{tabular}{|c|l|}
\hline$\leq 48 \mathrm{~h}$ & 1.0 \\
\hline$>48 \mathrm{~h}$ & 0.5 \\
\hline RLQ tenderness & 1.0 \\
\hline RLQ guarding & 2.0 \\
\hline Rebound tenderness & 1.0 \\
\hline Rovsing's sign & 2.0 \\
\hline Pyrexia & 1.0 \\
\hline Raised WBC & 1.0 \\
\hline Negative urinalysis & 1.0 \\
\hline
\end{tabular}

\section{References}

1. Wray CJ, Kao LS, Millas SG, Tsao K, Ko TC (2013) Acute appendicitis: Controversies in diagnosis and management. Curr Probl Surg 50(2): 5486.

2. Andersson RE (2004) Meta-analysis of the clinical and laboratory diagnosis of appendicitis. Br J Surg 91(1): 28-37.

3. L Allister, R Bachur, J Glickman, Horwitz B (2011) Serum markers in acute appendicitis. J Surg Res 168(1): 70-75.

4. SA Kabir, SI Kabir, R Sun, Sadaf Jafferbhoy, Ahmed Karim (2017) How to diagnose an acutely inflamed appendix; a systematic review of the latest evidence. International Journal of Surgery 40: 155-162.

5. Daniel J Shogilev, Nicolaj Duus, Stephen R Odom, Nathan I Shapiro (2014) Diagnosing appendicitis: evidence-based review of the diagnostic approach in 2014, West. J Emerg Med 15(7): 859-871.

6. Sand M, Bechara FG, Holland Letz T, Sand D, Mehnert G, et al. (2009) Diagnostic value of hyperbilirubinemia as a predictive factor for appendiceal perforation in acute appendicitis. Am J Surg 198(2): 193198.

7. Vaziri M, Pazouki A, Tamannaie Z, Maghsoudloo F, Pishgahroudsari $\mathrm{M}$, et al. (2013) Comparison of pre-operative bilirubin level in simple appendicitis and perforated appendicitis. Med J Islam Repub Iran 27(3): 109-112.

8. T Eren, E Tombalak, IA Ozemir, M Leblebici, S Ziyade, et al. (2016) Hyperbilirubinemia as a predictive factor in acute appendicitis. Eur J Trauma Emerg Surg 42: 471-476.

9. Vaziri M, Ehsanipour F, Pazouki A, Tamannaie Z, Taghavi R, et al. (2014) Evaluation of procalcitonin as a biomarker of diagnosis, severity and postoperative complications in adult patients with acute appendicitis. Med J Islam Repub Iran 28: 50

10. Bahadır Ceylan, Turan Aslan, Ahmet Çınar, Ayșe Ruhkar Kurt, Yasemin Akkoyunlu (2016) Can platelet indices be used as predictors of complication in subjects with appendicitis? Wien Klin Wochenschr 128(Suppl 8): S620-S625.

\section{ISSN: 2574-1241}

\section{DOI: 10.26717/BJSTR.2019.17.003055}

Mohammad Vaziri. Biomed J Sci \& Tech Res

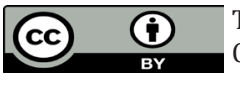

This work is licensed under Creative Commons Attribution 4.0 License

Submission Link: https://biomedres.us/submit-manuscript.php
11. L Lycopoulou, C Mamoulakis, E Hantzi, Demetriadis D, Antypas S, et al. (2005) Serum amyloid A protein levels as a possible aid in the diagnosis of acute appendicitis in children. Clin Chem Lab Med 43(1): 49-53.

12. A Kentsis, S Ahmed, K Kurek, Brennan E, Bradwin G, et al. (2012) Detection and diagnostic value of urine leucine-rich alpha-2glycoprotein in children with suspected acute appendicitis. Ann Emerg Med 60(1): 78-83.

13. AM Mills, DS Huckins, H Kwok, Baumann BM, Ruddy RM, et al. (2012) Diagnostic characteristics of S100A8/A9 in a multicenter study of patients with acute right lower quadrant abdominal pain. Acad Emerg Med 19(1): 48-55

14. Ambe PC, Orth V, Go Èdde D, Zirngibl H (2016) Improving the Preoperative Diagnostic Accuracy of Acute Appendicitis. Can Fecal Calprotectin Be Helpful? PLoS ONE 11(12): e0168769.

15. David S Huckins, Karen Copeland, Wesley Self, Cheryl Vance, Phyllis Hendry, et al. (2017) Diagnostic performance of a biomarker panel as a negative predictor for acute appendicitis in adult ED patients with abdominal pain. American Journal of Emergency Medicine 35(3): 418424.

16. Parks NA, Schroeppel TJ (2011) Update on imaging for acute appendicitis. Surg Clin North Am 91(1): 141-154.

17. Solomkin JS, Mazuski JE, Bradley JS, Keith A Rodvold, Ellie JC Goldstein, et al. (2010) Diagnosis and management of complicated intra-abdominal infection in adults and children: Guidelines by the Surgical Infection Society and the Infectious Diseases Society of America. Clin Infect Dis 50(2): 133-164.

18. Linam LE, Munden M (2012) Sonography as the first line of evaluation in children with suspected acute appendicitis. J Ultrasound Med 31(8): 1153-1157.

19. Kollar D, Mc Cartan DP, Bourke M, Cross KS, Dowdall J (2015) Predicting acute appendicitis? A comparison of the Alvarado score, the appendicitis inflammatory response score and clinical assessment. World J Surg 39: 104-109.

20. Ahn S, Lee H, Choi W, Ahn R, Hong JS, et al. (2016) Clinical Importance of the Heel Drop Test and a New Clinical Score for Adult Appendicitis. PLoS ONE 11(10): e0164574.

21. Han DG, Jeon MK, Kim HJ (2010) The most sensitive sign of meningeal irritation: heel-drop jarring test for meningitis. Med Hypotheses 74(6): 1084

22. Muhammad Usman Malik, Tara M Connelly, Faisal Awan, Frederik Pretorius, Constantino Fiuza Castineira, et al. (2017) The RIPASA score is sensitive and specific for the diagnosis of acute appendicitis in a western population. Int J Colorectal Dis 32(4): 491-497.

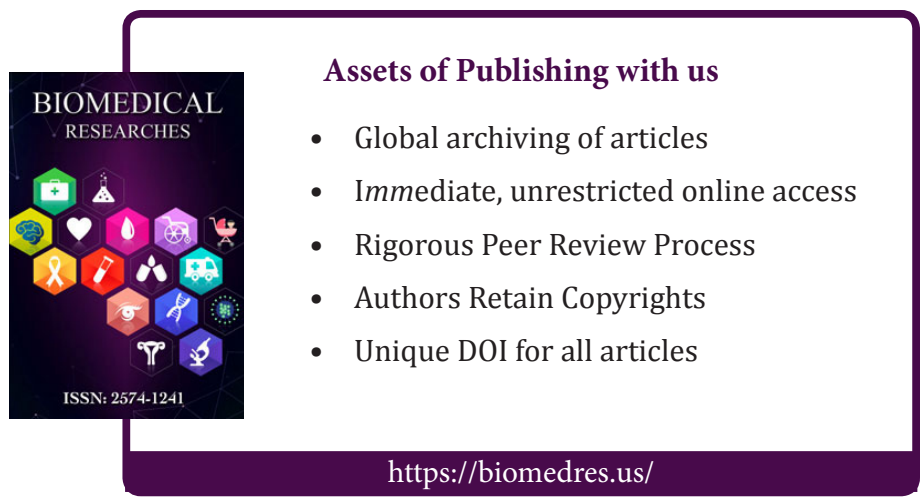

Copyright@ Mohammad Vaziri | Biomed J Sci \& Tech Res| BJSTR. MS.ID.003055. 